\title{
Rs2910164 in microRNA-146a confers an elevated risk of depression in patients with coronary artery disease by modulating the expression of NOS1
}

\author{
XINLING ZHANG ${ }^{*}$, QIANQIAN HUO*, WEI SUN, CHUNXIANG ZHANG, \\ ZONGYIN WU, BING XING and QIANG LI
}

Department of Cardiology, The First People's Hospital, Jining, Shandong 272011, P.R. China

Received January 21, 2016; Accepted January 13, 2017

DOI: $10.3892 / \mathrm{mmr} .2018 .8929$

\begin{abstract}
Depression has been well established as an independent predictor of mortality and cardiac morbidity rates in patients with coronary artery disease (CAD). Evidence has shown that single nucleotide polymorphisms located in pre-microRNA (miRNA) or mature miRNA may modify various biological processes and affect the process of carcinogenesis, and the downregulation of neuronal nitric oxide synthase 1 (NOS1) can induce depression. It has been shown that NOS1 is the target gene of miR-146a, and that the rs2910164 G/C polymorphism can downregulate the expression of miR-146a. In the present study, computational analysis was used to identify the target of miR-146a, and a luciferase reporter assay system was used to validate NOS1 as a target gene of miR-146a. In addition, U251 cells were treated with miR-146a mimics/inhibitors to verify the negative regulatory association between miR-146a and NOS1. Reverse transcription-quantitative polymerase chain reaction analysis and western blot analysis were used to estimate the mRNA expression of NOS1 and the expression of miR-146a. The results showed that the 'seed sequence' was located within the 3'-untranslated region of NOS1 by searching an online miRNA database (www.mirdb.org), and the luciferase reporter assay confirmed that NOS1 was a direct target gene of miR-146a. It was also found that the mRNA and protein expression levels of NOS1 in U251 cells treated with miR-146a mimics and NOS1 small interfering RNA were substantially downregulated, compared with cells treated with the scramble control. The cells treated with miR-146a
\end{abstract}

Correspondence to: Dr Qiang Li, Department of Cardiology, The First People's Hospital, 6 Jiankang Road, Jining, Shandong 272011, P.R. China

E-mail: caddepression@126.com

*Contributed equally

Key words: rs2910164, microRNA-146a, depression, coronary artery disease, nitric oxide synthase 1 inhibitors showed increased expression of NOS1. In addition, the presence of a minor allele of the rs2910164 polymorphism was significantly associated with risk of depression in patients with CAD. Taken together, the findings indicated a decreased risk of depression in the patients with CAD who were carriers of the miR-146a rs2910164 C allele, and this association may be attributed to its ability to compromise the expression of miR-146a, and thereby increase the expression of its target gene, NOS1.

\section{Introduction}

One of the leading factors causing individuals to live for years with disability is depression, the incidence of which is increasing worldwide (1). When combined with a chronic medical condition, depression has a marked effect on compromised health (2). In America, $>17,000,000$ adults have survived an acute coronary syndrome (ACS) event as at 2010, and the number of new survivors each year is 1,200,000 (3). In every five of these individuals, two report marked symptoms of depression, with symptoms persisting for a long duration following discharge $(4,5)$. Therefore, up to $7,000,000$ individuals in America with coronary artery disease (CAD) suffer from clinically significant depression, of which there are 500,000 new cases each year, placing a burden on public health (6). There is high possibility that the two often occur in combination and the occurrence of either signals the increased possibility of the onset of the other. Therefore, the focus has shifted to the complicated association between depression and ACS. For example, the presence of depression and/or minimally increased symptoms of depression appear to be a reliable risk factor and prognostic factor of CAD relapse and mortality rates from all causes (4).

Individuals suffering from occasional depression are distinct from those who have a history of depression, as demonstrated in a previous study of CAD severity performed in a population exhibiting CAD comorbidities with depression. In a study performed in 39 patients recently diagnosed with CAD and who met the criteria for major depressive disorder (MDD), patients who had history of depression exhibited less severe CAD compared with patients without history of depression (7). The direct visualization of coronary arteries via angiogram 
was used to assess the severity of CAD, which was expressed as the number of occluded coronary arteries with $>50 \%$ stenosis. There appeared to be an association between the incidence of MDD and severity of CAD, whereas no association was found between a new MDD event and the severity of CAD in patients with a history of MDD. However, the samples in the study did not include the full spectrum of patients with ACS, and the significance level of the difference in severity of CAD between patients with recurrent and incident MDD was only $\mathrm{P}=0.07$.

MicroRNAs (miRNAs) have a crucial regulatory role in stress responses and cardiac homeostasis. miRNAs have 'nodal' control on important biological processes via the destabilizing of messenger RNAs encoding proteins involved in cell growth, metabolism, programmed death pathways and calcium signaling (8). Generally, individual miRNA-mRNA interactions marginally decrease the levels of target mRNAs, suggesting that miRNAs are 'fine tuners' in the functioning of cells (9). However, when certain miRNA levels are deliberately controlled, particularly when all types of a specific miRNA are genetically removed, notable phenotypes can be triggered $(10,11)$.

Considering the fact that NOS1 is functionally involved in the pathogenesis of depression in patients with CAD $(12,13)$, NOS1 is a potential target of miR-146a, as the presence of rs2910164 reduces the expression of miR-146a (14). The present study aimed to verify the miR-146a/NOS1 association in U251 cells and examine the association between the miR-146a rs2910164 polymorphism and the development of depression in patients with CAD.

\section{Materials and methods}

Sample collection. Peripheral blood samples from 865 patients with CAD, including 412 patients who experienced depression following CAD and 453 who did not, were collected at the Department of Cardiology of The First People's Hospital (Jining, China) between June 2013 and December 2014. Patients experiencing current alcohol and/or substance abuse, current psychotic disorder, active suicidal or homicidal thoughts, or cognitive impairment were excluded from the study. The study was performed according to the latest version of the Declaration of Helsinki. The patients provided signed informed consent for participation in the study following explanation of potential risks. The Ethics and Research Committees of the First People's Hospital at Jining (Jining, China) approved the study.

Target prediction and functional analysis. By scanning the mostly used target gene prediction databases online miRNA database (www.mirdb.org), the putative target genes of the miR-146a were pooled from the three databases in total. Experimental validation on the majority of the target genes was performed.

Genotyping by direct sequencing. The TaqMan genotyping kit (Applied Biosystems; Thermo Fisher Scientific, Inc., Waltham, MA, USA) was used to determine the genotype of rs2910164 according to the manufacturer's protocol in each participant.

RNA isolation and reverse transcription-quantitative polymerase chain reaction ( $R T-q P C R)$ analysis. RT-qPCR analyses were performed to determine the expression level of miR-146a and NOS1 mRNA in U251 cells. The Absolutely RNA ${ }^{\mathrm{TM}}$ RT-PCR miniprep kit (Qiagen, Inc., Valencia, CA, USA) was used to purify the total RNA from U251 cells in accordance with the manufacturer's protocol. A total NanoDrop ND-3300 ${ }^{\circledR}$ fluorospectrometer (Thermo Fisher Scientific, Inc.) was used to estimate the density of the RNA at a final concentration of $2 \mathrm{ng} / \mu \mathrm{g}$. For further experiments, the RNA was placed in microcentrifuge tube and stored at $-80^{\circ} \mathrm{C}$.

For detecting the expression levels of mature miR-146a, TaqMan miRNA assays (ABI PRISM; Thermo Fisher Scientific, Inc.) with the stem-loop method were used. The High-Capacity cDNA reverse transcription kit (Applied Biosystems; Thermo Fisher Scientific, Inc.) was used to perform the RT reaction to synthesize cDNA (NOS1), according to the manufacturer's protocol, with a mixture of RT primer $(3 \mu \mathrm{l})$ and $10 \mathrm{ng}$ total RNA. The RT reactions were performed at $16^{\circ} \mathrm{C}$ for $30 \mathrm{~min}$ (primer binding), $42^{\circ} \mathrm{C}$ for $30 \mathrm{~min}$ (cDNA synthesis) and $85^{\circ} \mathrm{C}$ for $5 \mathrm{~min}$ (inactivation of enzyme), followed by maintenance at $4^{\circ} \mathrm{C}$. TaqMan primers ( $2 \mu \mathrm{l}$; Qiagen, Inc.) and $1.5 \mu \mathrm{l}$ cDNA were used for the subsequent PCR analysis, according to the manufacturer's protocol. The sequences of the primers were: miR-146a (forward: 5'-ACACTCCAGCTGGGTGAGAAC TGAATTCC-3'; reverse: 5'-CTCAACTGGTGTCGTGGA GTCGGCAATTCAGTTGAGAACCCATGG-3'); NOS1 (forward: 5'-AGACGCACGAAGATAGTTGAC-3'; reverse: 5'-CCGAAGCTCCAGAACTCAC-3'); $\beta$-actin (forward: 5'-CTCTTCCAGCCTTCCTTCСТ-3'; reverse: 5'-TCATCG TACTCCTGCTTGCT-3'); U6 (forward: 5'-CTCGCTTCG GCAGCACA-3'; reverse: 5'-AACGCTTCACGAATTTGC GT-3'). A TaqMan ${ }^{\circledR}$ miRNA assay (Applied Biosystems; Thermo Fisher Scientific, Inc.) was used to detect the expression of NOS1 and miR-146a. The $2^{-\Delta \Delta \mathrm{Cq}}$ value (15) was used to calculate the relative gene expression levels between the different treatment groups. The expression of U6 was used as the internal control of the reaction. All experiments were performed in triplicate.

Cell culture and transfection. The U251 cells (ATCC, Manassas, VA, USA) were cultured in Dulbecco's modified Eagle's medium (Invitrogen; Thermo Fisher Scientific, Inc.) supplemented with $100 \mathrm{U} / \mathrm{ml}$ penicillin, 10\% fetal bovine serum (Invitrogen; Thermo Fisher Scientific, Inc.) and $100 \mu \mathrm{g} / \mathrm{ml}$ streptomycin, in an atmosphere of $5 \% \mathrm{CO}_{2} / 95 \%$ air at $37^{\circ} \mathrm{C}$ until use. When confluence reached $80 \%$, Lipofectamine ${ }^{\circledR} 2000$ (Invitrogen; Thermo Fisher Scientific, Inc.) was used to perform the transfection procedures according to the manufacturer's protocol.

Luciferase assay. The 3'-untranslated region (UTR) of NOS1 containing the binding site of miR-146a was amplified via PCR. A Dual Luciferase Reporter Assay system (Promega Corporation, Madison, WI, USA) was used to measure the activity of luciferase. The 3'-UTR of NOS1 and the mutated type were inserted into the empty TOP-FLASH, FOP-FLASH plasmids (EMD Millipore, MA, USA) to construct the luciferase reporter, according to the manufacturer's protocol. Lipofectamine ${ }^{\circledR} 2000$ (Invitrogen; Thermo Fisher Scientific, Inc.) was used to co-transfect U251 cells with miRNA-481, and Renilla was used as an internal control in accordance 
with the manufacturer's protocol. At $48 \mathrm{~h}$ post-transfection, the Dual-Luciferase Reporter Assay system (Promega Corporation) was used to detect the luciferase activity of the cells, compared with the activity of Renilla (internal control). Each independent experiment was performed in triplicate and the average of the report data was accepted.

Western blot analysis. Following all treatments, the U251 cells were harvested and washed twice using ice cold PBS. RIPA buffer (Sigma-Aldrich; Merck Millipore, Darmstadt, Germany) containing $50 \mathrm{mM}$ Tris $\mathrm{Cl}, 50 \mathrm{mM} \mathrm{NaF}, 150 \mathrm{mM}$ $\mathrm{NaCl}, 1 \%$ sodium deoxycholate $5 \mathrm{mM}$ EDTA, $0.1 \% \mathrm{SDS} / 1 \%$ aprotinin, $1 \%$ Nonidet P-40 and $0.1 \mathrm{mM} \mathrm{Na}_{3} \mathrm{VO}_{4}$ (pH 7.4), with a protease inhibitor cocktail (Promega Corporation) was used to lyse U251 cells, and the cellular lysates were centrifuged at $13,000 \mathrm{x}$ g for $15 \mathrm{~min}$ at $48^{\circ} \mathrm{C}$. A BCA assay kit (BioTeke Corporation, Beijing, China) was used to measure the concentration of the supernatant protein in accordance with the manufacturer's protocol, following which the proteins $(40 \mu \mathrm{g})$ were heated in boiling water for $5 \mathrm{~min}$ with loading buffer. Subsequently, a $10 \%$ sodium dodecyl sulfate polyacrylamide gel was used to isolate the proteins, followed by semi-dry transfer onto a polyvinylidene fluoride membrane (Bio-Rad Laboratories, Inc., Hercules, CA, USA). The blot was then incubated with mouse antibody against $\beta$-actin (sc-418965; 1:2,000; Santa Cruz Biotechnology, Inc., Shanghai, China) and mouse antibodies against NOS1 (sc-136006; 1:1,000; Santa Cruz Biotechnology, Inc.) at $4^{\circ} \mathrm{C}$ overnight. In order to enhance chemiluminescence (Boster Systems, Inc., Pleasanton, CA, USA), the blot was incubated with goat anti-mouse secondary antibody conjugated to horseradish peroxidase (BA1075; 1:3,000; Boster Systems, Inc.) for $90 \mathrm{~min}$ at room temperature. ImageJ software version 1.46r (National Institutes of Health, Bethesda, MA, USA) was used to quantify the results. Following normalization to individual $\beta$-actin levels, the proportions of the expression of NOS1 and miR-146a were determined. All samples were run in triplicate.

Statistical analysis. All data are expressed as the mean \pm standard deviation. $\mathrm{P}<0.05$ was considered to indicate a statistically significant difference. The differences in the demographic and clinicopathological parameters between the two groups were analyzed using Student's t-test or $\chi^{2}$ test. Logistic regression analysis was used to determine the difference in genotype between the two groups with the potential confounding factors adjusted. All statistical analyses were performed using SPSS version 17.0 (SPSS, Inc., Chicago, IL, USA).

\section{Results}

Demographic, clinicopathological and genotypic parameters of participants. A total of 412 patients with CAD with depression and 453 patients with CAD without depression were recruited for the present study. Student's t-test was used to analyze the gender, age, age of onset, cigarette smoking, family history, levels of total cholesterol, triglyceride and fasting glucose, blood pressure and body mass index between these two groups, the details of which are shown in Table I. All participants were divided into three groups by rs2910164 genotype: CC, CG and GG, and logistic regression analysis was performed. The $95 \%$ confidence interval $(\mathrm{CI})$ was $0.42-0.73$ and odds ratio $(\mathrm{OR})$ was $0.56(\mathrm{P}=0.001)$. All details are shown in Table II. The participants were also divided into two groups by frequency: $\mathrm{C}$ and $\mathrm{G}$, and logistic regression analysis revealed a $95 \% \mathrm{CI}$ of $0.46-0.70$ and $\mathrm{OR}$ of $0.57(\mathrm{P}=0.001)$. All details are shown in Table II.

NOS1 is a virtual target of miR-146a. miR-146a has been found to be commonly involved in the pathogenesis of various human diseases, including skin cancer, hepatocellular carcinoma and CAD (16-18). The present study aimed to investigate the molecular mechanism, including the signaling pathways and potential regulator of NOS1, which may be functionally involved in the regulation of depression in the patients with CAD. A prediction algorithm revealed that there was complementarity between the NOS1 3'-UTR and the seed sequence of miR-146a. To validate whether miR-146a was able to target NOS1, reporter constructs were generated; these contained either a wild-type or a mutant NOS1, reporter constructs were generated; genes (Fig. 1).

In order to confirm the regulatory association between NOS1 and miR-146a, a luciferase reporter assay system was used. Luciferase reporter plasmids were constructed harboring the wild-type 3'-UTR and mutant 3'-UTR (Fig. 2). The reporter luciferase activity of the wild-type 3'-UTR was significantly inhibited by miR-146a in the miR-146a mimic group, compared with the scramble and blank control (Fig. 2), indicting the negative regulatory association between miR-146a and NOS1. Comparing the luciferase activity of the scramble control, blank control and cells carrying the mutant NOS1 3'-UTR constructs indicated NOS1 as the direct target gene of miR-146a, with the binding site located at the segment which was mutated. Therefore, NOS1 was a direct target of miR-146a, and the binding site was located at the 3'-UTR of NOS1.

Expression levels of miR-146a and NOS1 differ between treatment groups. In order to determine the role of miR-146a in mediating the mechanism in patients with CAD and depression, the expression of miR-146a in U251 cells was reduced using an miR-146a inhibitor to inhibit its expression. The expression levels of miR-146a and NOS1 were determined using RT-qPCR and western blot analyses. As shown in Fig. 3A, the protein expression levels of NOS1 in U251 cells treated with miR-146a mimics and NOS1 siRNA were lower, compared with that in the scramble control, indicating a negative regulatory association between miR-146a and NOS1. The miR-146a inhibitor was used to inhibit its expression, and the miR-146a inhibitor treatment group exhibited higher protein expression of NOS1, confirming the negative regulatory association between miR-146a and NOS1.

As shown in Fig. 3B, the mRNA expression levels of NOS1 in U251 cells treated with miR-146a mimics and NOS1 siRNA were lower, compared with that in the scramble control group, indicating a negative regulatory association between miR-146a and NOS1 mRNA. The miR-146a inhibitor was used to suppress its expression, and the cells in the miR-146a inhibitor treatment group exhibited a markedly increased mRNA level of NOS1. Transfection with miR-146a inhibitor reversed this effect; therefore, the results revealed there was a negative regulatory association between miR-146a and NOS1. 
Table I. Demographic and genotypic characteristics of patients with CAD with or without depression.

\begin{tabular}{|c|c|c|c|}
\hline Characteristic & $\begin{array}{c}\text { CAD with } \\
\text { depression }(n=412)\end{array}$ & $\begin{array}{c}\text { CAD without } \\
\text { depression }(n=453)\end{array}$ & P-value \\
\hline Gender (male/female) & $157 / 255$ & $166 / 287$ & \\
\hline Age in years (range) & $48.55 \pm 11.2(18-75)$ & $47.35 \pm 8.2(20-78)$ & 0.44 \\
\hline Single/recurrent episode & $115 / 297$ & - & \\
\hline Family history (+/-) & $218 / 194$ & - & \\
\hline Age of onset (years) & $35.2 \pm 11.4$ & - & \\
\hline Cigarette smoking n (\%) & $35(22.56)$ & $38(24.16)$ & 0.71 \\
\hline Total cholesterol $\left(\mathrm{mg} \mathrm{dl}^{-1}\right)$ & $214.21 \pm 45.3$ & $208.28 \pm 41.3$ & 0.08 \\
\hline Triglyceride $\left(\mathrm{mg} \mathrm{dl}^{-1}\right)$ & $133.24 \pm 70.2$ & $113.26 \pm 55.2$ & 0.25 \\
\hline Fasting glucose $\left(\mathrm{mg} \mathrm{dl}^{-1}\right)$ & $95.64 \pm 21.6$ & $93.24 \pm 11.5$ & 0.81 \\
\hline Blood pressure $_{\text {sys }}(\mathrm{mmHg})$ & $128.23 \pm 14.3$ & $120.15 \pm 12.1$ & 0.15 \\
\hline Blood pressure $_{\text {dias }}(\mathrm{mmHg})$ & $76.14 \pm 8.3$ & $71.12 \pm 4.6$ & 0.26 \\
\hline Body mass index $\left(\mathrm{kg} \mathrm{m}^{-2}\right)$ & $25.24 \pm 3.3$ & $22.31 \pm 4.1$ & 0.95 \\
\hline
\end{tabular}

Data (with the exception of gender, recurrence, family history and smoking) are presented as the mean \pm standard deviation. CAD, coronary artery disease.

Table II. Association between genotypes and allele frequencies of rs2910164 polymorphisms and the risk of major depression in patients with CAD.

\begin{tabular}{|c|c|c|c|}
\hline $\begin{array}{l}\text { rs2910164 } \\
\text { polymorphism }\end{array}$ & $\begin{array}{l}\text { CAD with depression } \\
\quad(n=412) n(\%)\end{array}$ & $\begin{array}{l}\text { CAD without depression } \\
(\mathrm{n}=453) \mathrm{n}(\%)\end{array}$ & Significance \\
\hline \multicolumn{4}{|l|}{ Genotype } \\
\hline GG & $160(39)$ & $240(53)$ & $\begin{aligned} \mathrm{OR} & =0.56 \\
95 \% \mathrm{CI} & =0.42-0.73\end{aligned}$ \\
\hline GC & $185(45)$ & $185(41)$ & \\
\hline $\mathrm{CC}$ & $67(16)$ & $28(6)$ & \\
\hline $\mathrm{GC} / \mathrm{CC}$ & $252(61)$ & $213(47)$ & $\mathrm{P}<0.001$ \\
\hline \multicolumn{4}{|l|}{ Allele frequency } \\
\hline G & $505(61)$ & $665(73)$ & $\begin{aligned} \mathrm{OR} & =0.57 \\
95 \% \mathrm{CI} & =0.46-0.70\end{aligned}$ \\
\hline $\mathrm{C}$ & 319 (39) & $241(27)$ & $\mathrm{P}<0.001$ \\
\hline
\end{tabular}

CAD, coronary artery disease; OR, odds ratio; CI, confidence interval.

\section{Discussion}

Accumulating evidence has shown that depression is a risk factor for cardiac morbidity and mortality rates in patients who have had CAD in the previous three decades (19). However, several questions remain to be elucidated and there are also debates regarding this finding. Whether depression is not only a risk factor but also a causal risk factor for adverse CAD results, and which biobehavioral mechanisms are involved remain significant scientific questions regarding patients with CAD and depression $(20,21)$. In clinical settings, it remains to be elucidated whether depression in patients with CAD is treatable and whether cardiac event-free-survival can be improved by treatment (22).
Nitric oxide (NO) directly modifies protein thiols (S-nitrosylation) at the post-translational level and activates signaling pathways dependent on cyclic guanosine monophosphate, thereby having a crucial regulatory role in cardiac function (23). NO originating from active neuronal NOS1 is associated with S-nitrosylation of crucial sarcoplasmic reticulum (SR) $\mathrm{Ca}^{2+}$ handling proteins (24). It is not surprising that the dysfunction of NOS is an important contributor to vascular pathophysiology due to the pivotal role of NO signaling in inflammation, thrombosis, smooth muscle proliferation and endothelial function (25). Previous loss of function and gain of function genetic studies have shown the significance of NOS3 in vascular homeostasis, with deletion aggravating vascular remodeling and neointimal medial thickening following 


$\begin{array}{ll}\text { hsa-miR-146a } & \text { 5'-UUGgGUACCUUAAGUCAAGAGU-3' } \\ \text { Wild-type NOS1 } & \text { 3'-CT CT TCTTCT GTATAGT TCTCA-5' } \\ \text { hsa-miR-146a } & \text { 5'-UUGGGUACCUUAAGUCAAGAGU-3 } \\ \text { Mutant NOS1 } & \text { 3'-CT CT TCTTCT GTATGAGGTCAA-5' }\end{array}$

Figure 1. NOS1 is as candidate target gene of miR-146a. NOS1 was identified as a candidate target gene of miR-146a in U251 cells with the 'seed sequence' in the 3'untranslated region of NOS1. NOS1, nitric oxide synthase 1; miR, microRNA.

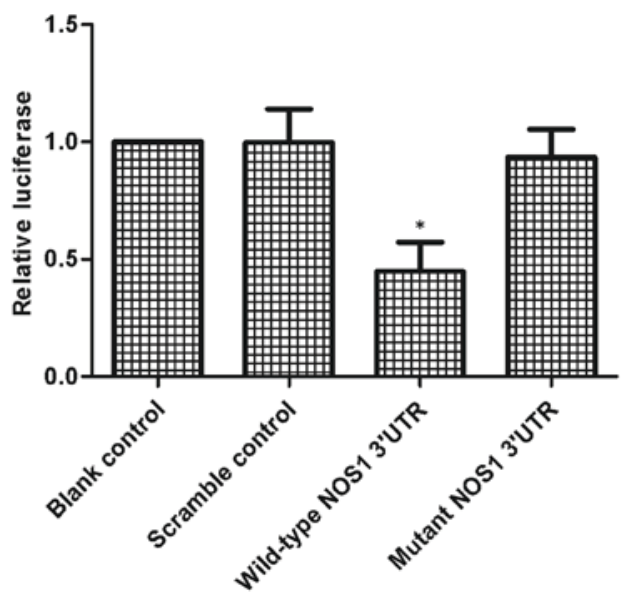

Figure 2. NOS1 is a direct target of miR-146a. Compared with the blank control and scramble control, miR-146a mimics significantly inhibited the reporter luciferase activity of the wild-type NOS1 3'-UTR $(\mathrm{P}<0.05$ vs. scramble control), but not that of the mutant NOS1 3'-UTR ("P $>0.05$ vs. scramble control). The relative luciferase activities of the scramble control and mutant NOS1 3'-UTR constructs were comparable. miR, microRNA; 3'-UTR, 3'untranslated region; NOS1, nitric oxide synthase 1.

disruption (26); whereas overexpressed endothelial-targeted NOS3 decreases atherosclerosis in ApoE-null mice and inhibits vascular remodeling $(27,28)$. Of note, oxidant-coupled hyperpolarization and NO-dependent vasorelaxation can be inhibited by the deletion of NOS3 (29). Although less NO is generated by uncoupled NOS3, its synthesis of $\mathrm{O}^{-}$, which becomes $\mathrm{H}_{2} \mathrm{O}_{2}$ by $\mathrm{Cu}, \mathrm{Zn}$-superoxide dismutase, leads to vasodilation (30). The latter is coupled to oxidated $\mathrm{C} 46$ residues in protein kinase G1K to generate an internal disulfide bond and a cGMP-independently activated kinase (31). In the brain, the richest form is NOS1, which has an extensive effect in synaptic signaling, and is involved in neuronal plasticity, memory, learning, and a variety of psychiatric conditions, including schizophrenia and depression $(32,33)$. NOS1 serves a more specific regulatory role in the hypothalamic-pituitary-adrenal axis and the serotonin pathway $(34,35)$. A study by Pogun and Kuhar (35) demonstrated that, via their mutual PDZ-binding motifs, they are coupled to $\mathrm{Ca}^{2+}$-permeable $\mathrm{N}$-methyl-D-aspartate receptors at the postsynaptic density (PSD-95). In several regions of the brain, including the hippocampus in animal models, there is a stress response in addition to the increased expression of NOS1 caused by chronic stress (34). A number of animal experiments have shown that, in stress models, drugs, which suppress NOS exhibit antidepressant-analog behavioral actions (36).
A
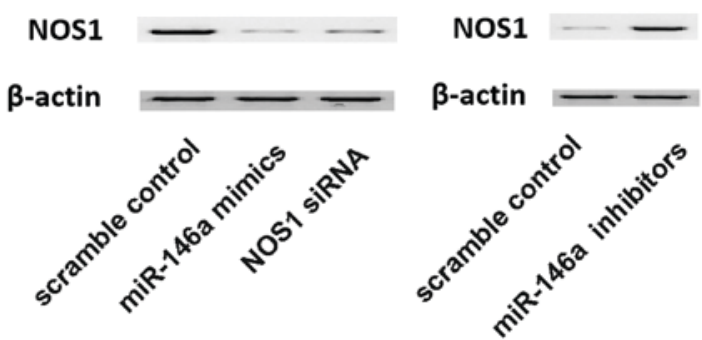

B

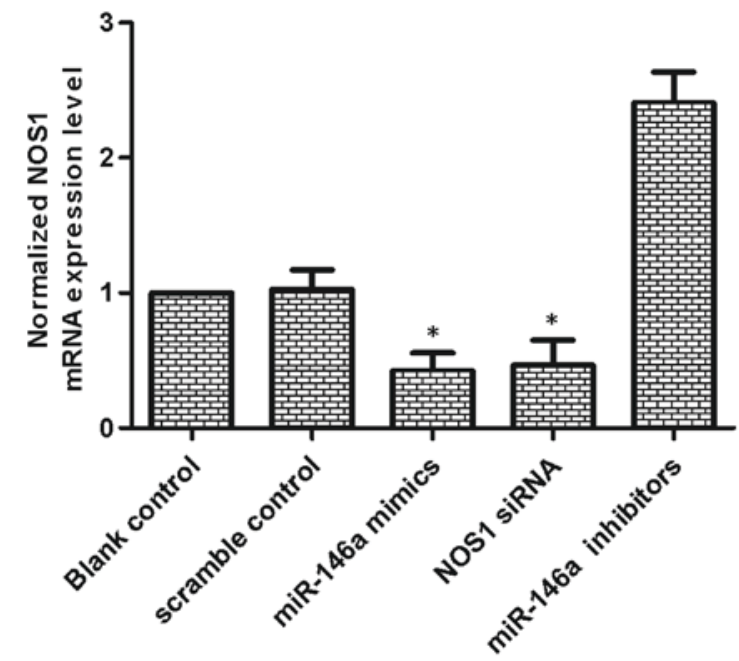

Figure 3. Inhibition of miR-146a induces the upregulation of NOS1 (A) Protein and (B) mRNA expression levels of NOS1 were compared in U251 cells transfected with the miR-146a mimics, blank control and scramble control. Expression levels were lower in the mimic-transfected cells, compared with those in the scramble control $(\mathrm{P}<0.05$ vs. scramble control). The protein and mRNA expression levels of NOS1 in the U251 cells transfected with miR-146a mimics and mutant NOS1 3'untranslated region constructs were also compared, which showed comparable relative expression levels ("P>0.05 vs. scramble control). miR, microRNA; NOS1, nitric oxide synthase 1; siRNA, small interfering RNA.

It has been shown that miR-146a has a critical effect on tumorigenesis, cell differentiation, proliferation and apoptosis (37). In 2008, Jazdzewski et al (14) showed that a common polymorphism, known as rs2910164, in the pre-miR-146a sequence, altered the expression of mature miR-146a and had an important effect on tumorigenesis. The correlation between the rs $2910164 \mathrm{G}>\mathrm{C}$ polymorphism and cancer risk, including gastrointestinal tumors, have been investigated extensively in substantial meta-analyses and reviews over the last 3 years (38). The association between the rs2910164 polymorphism and the risk of gastric cancer has been assessed in nine of these (39). The findings were consistent with no significant correlation between gastric cancer and the rs2910164 polymorphism. Whereas risk and decreased survival rates in patients with glioma are associated with the CC genotype, miR-146a (rs2910164) GC polymorphisms are important in papillary thyroid carcinoma (40). A meta-analysis examined conflicting studies regarding predisposition to cancer. There was no pattern between tumor type and the SNP. By contrast, a correlation was reported between elevated risk of cancer in an Asian population and GG variant genotypes (41), which 
may indicate the heterogeneity of the disorder. It has also been reported that the G-allele is correlated with pulmonary tuberculosis in various directions in Tibetan (risk) and Han (protection) populations regarding mycobacterial infections (42). Data were compiled, which showed evidence of an association between the GC miRSNP-146a and leprosy in a Brazilian population. Family-based and case control study designs were used, and a correlation between the C-allele and predisposition to leprosy was demonstrated, with age-at-diagnosis being a critical factor adjusting this correlation, which was also described previously in leprosy $(43,44)$. In the present study, NOS1 was identified as a direct target of miR-146a using computational analysis and a luciferase assay, which was further confirmed by the observation that the mRNA and protein expression levels of NOS1 in U251 cells treated with miR-146a mimics and NOS1 siRNA were substantially downregulated, compared with those in the scramble control, whereas cells treated with miR-146a inhibitors showed increased expression of NOS1. In the present association study, patients with CAD, including 412 patients with depression and 453 patients without depression, were recruited, who were further divided into three groups by rs2910164 genotype: CC, CG and GG. Logistic regression analysis was performed, which revealed that the presence of the minor allele of the polymorphism was significantly associated with the risk of depression in patients with CAD $(95 \%$ CI, 0.42-0.73; OR, 0.56; $\mathrm{P}<0.001)$. It was also shown that the allele frequency was significantly associated with the risk of depression in CAD (95\% CI, 0.46-0.7; OR, 0.57; P<0.001).

In conclusion, the results of the present study indicated a decreased risk of depression in patients with CAD who are carriers of the miR-146a rs2910164 C allele, and this association may be attributed to its ability to compromise the expression of miR-146a, and thereby increase the expression of its target gene, NOS1.

\section{Acknowledgements}

Not applicable.

\section{Funding}

This study was sponsored by the Shandong Province Medical Science and Technology Development Plan Youth Projects (grant no. 2013WS0054).

\section{Availability of data and materials}

All data generated or analyzed during this study are included in this published article.

\section{Authors' contributions}

XZ: Study planning, data analysis and interpretation, and preparation of the manuscript; QH: Study planning, data collection, preparation of the manuscript, and literature analysis; WS: Study planning, data collection, and preparation of the manuscript; CZ: Data collection, data analysis, preparation of the manuscript, and literature analysis; ZW: Data interpretation, preparation of the manuscript, and literature analysis;
BX: Data analysis and interpretation, and preparation of the manuscript; and, QL: Data collection and sourcing of funds.

\section{Ethics approval and consent to participate}

The study was performed according to the latest version of the Declaration of Helsinki. The Ethics and Research Committees of the First People's Hospital at Jining (Jining, China) approved the study.

\section{Consent for publication}

The patients provided signed informed consent for participation in the study following explanation of potential risks.

\section{Competing interests}

The authors declare that they have no competing interests.

\section{References}

1. Lopez AD, Mathers CD, Ezzati M, Jamison DT and Murray CJ: Global and regional burden of disease and risk factors, 2001 : Systematic analysis of population health data. Lancet 367: 1747-1757, 2006.

2. Moussavi S, Chatterji S, Verdes E, Tandon A, Patel V and Ustun B: Depression, chronic diseases and decrements in health: Results from the World Health Surveys. Lancet 370: 851-858, 2007.

3. Writing Group Members; Lloyd-Jones D, Adams RJ, Brown TM, Carnethon M, Dai S, De Simone G, Ferguson TB, Ford E, Furie K, et al: Heart disease and stroke statistics-2010 update: A report from the American Heart Association. Circulation 121: e46-e215, 2010.

4. Carney RM and Freedland KE: Depression in patients with coronary artery disease. Am J Med 121 (11 Suppl 2): S20-S27, 2008.

5. Bush DE, Ziegelstein RC, Patel UV, Thombs BD, Ford DE, Fauerbach JA, McCann UD, Stewart KJ, Tsilidis KK, Patel AL, et al: Post-myocardial infarction depression. Evid Rep Technol Assess (Summ): 1-8, 2005.

6. Enas EA, Kuruvila A, Khanna P, Pitchumoni CS and Mohan V: Benefits \& risks of statin therapy for primary prevention of cardiovascular disease in Asian Indians-a population with the highest risk of premature coronary artery disease \& diabetes. Indian J Med Res 138: 461-491, 2013.

7. Freedland KE, Carney RM, Lustman PJ, Rich MW and Jaffe AS: Major depression in coronary artery disease patients with vs. without a prior history of depression. Psychosom Med 54: 416-421, 1992.

8. Dorn GW II: MicroRNAs: Redefining mechanisms in cardiac disease. J Cardiovasc Pharmacol 56: 589-595, 2010.

9. Kwon C, Han Z, Olson EN and Srivastava D: MicroRNA1 influences cardiac differentiation in Drosophila and regulates Notch signaling. Proc Natl Acad Sci USA 102: 18986-18991, 2005.

10. Zhao Y, Ransom JF, Li A, Vedantham V, von Drehle M, Muth AN, Tsuchihashi T, McManus MT, Schwartz RJ and Srivastava D: Dysregulation of cardiogenesis, cardiac conduction and cell cycle in mice lacking miRNA-1-2. Cell 129: 303-317, 2007.

11. He Y, Zhou Y, Xi Q, Cui H, Luo T, Song H, Nie X, Wang L and Ying B: Genetic variations in microRNA processing genes are associated with susceptibility in depression. DNA Cell Biol 31: 1499-1506, 2012.

12. Bruenig D, Morris CP, Mehta D, Harvey W, Lawford B, Young RM and Voisey J: Nitric oxide pathway genes (NOS1AP and NOS1) are involved in PTSD severity, depression, anxiety, stress and resilience. Gene 625: 42-48, 2017.

13. Sarginson JE, Deakin JF, Anderson IM, Downey D, Thomas E, Elliott R and Juhasz G: Neuronal nitric oxide synthase (NOS1) polymorphisms interact with financial hardship to affect depression risk. Neuropsychopharmacology 39: 2857-2866, 2014.

14. Jazdzewski K, Murray EL, Franssila K, Jarzab B, Schoenberg DR and de la Chapelle A: Common SNP in pre-miR-146a decreases mature miR expression and predisposes to papillary thyroid carcinoma. Proc Natl Acad Sci USA 105: 7269-7274, 2008. 
15. Livak KJ and Schmittgen TD: Analysis of relative gene expression data using real-time quantitative PCR and the 2(-Delta Delta C(T)) method. Methods 25: 402-408, 2001.

16. Forloni M, Dogra SK, Dong Y, Conte D Jr, Ou J, Zhu LJ, Deng A, Mahalingam M, Green MR and Wajapeyee N: miR-146a promotes the initiation and progression of melanoma by activating Notch signaling. Elife 3: e01460, 2014.

17. Huang S, He R, Rong M, Dang Y and Chen G: Synergistic effect of MiR-146a mimic and cetuximab on hepatocellular carcinoma cells. Biomed Res Int 6: 384121, 2014.

18. Wang J, Yan Y, Song D and Liu B: Reduced plasma miR-146a is a predictor of poor coronary collateral circulation in patients with coronary artery disease. Biomed Res Int 2016: 4285942, 2016.

19. Charlson FJ, Stapelberg NJ, Baxter AJ and Whiteford HA: Should global burden of disease estimates include depression as a risk factor for coronary artery disease? BMC Med 9: 47, 2011.

20. Kuper H, Nicholson A, Kivimaki M, Aitsi-Selmi A, Cavalleri G, Deanfield JE, Heuschmann P, Jouven X, Malyutina S, Mayosi BM, et al: Evaluating the causal relevance of diverse risk markers: Horizontal systematic review. BMJ 339: b4265, 2009.

21. Carney RM, Freedland KE, Miller GE and Jaffe AS: Depression as a risk factor for cardiac mortality and morbidity: A review of potential mechanisms. J Psychosom Res 53: 897-902, 2002.

22. Carney RM and Freedland KE: Treatment-resistant depression and mortality after acute coronary syndrome. Am J Psychiatry 166: 410-417, 2009.

23. Tamargo J, Caballero R, Gómez R and Delpón E: Cardiac electrophysiological effects of nitric oxide. Cardiovasc Res 87: 593-600, 2010

24. Lima B, Forrester MT, Hess DT and Stamler JS: S-nitrosylation in cardiovascular signaling. Circ Res 106: 633-646, 2010.

25. Heitzer T, Schlinzig T, Krohn K, Meinertz T and Münzel T: Endothelial dysfunction, oxidative stress and risk of cardiovascular events in patients with coronary artery disease. Circulation 104: 2673-2678, 2001

26. Moroi M, Zhang L, Yasuda T, Virmani R, Gold HK, Fishman MC and Huang PL: Interaction of genetic deficiency of endothelial nitric oxide, gender and pregnancy in vascular response to injury in mice. J Clin Invest 101: 1225-1232, 1998.

27. van Haperen R, de Waard M, van Deel E, Mees B, Kutryk M, van Aken T, Hamming J, Grosveld F, Duncker DJ and de Crom R: Reduction of blood pressure, plasma cholesterol and atherosclerosis by elevated endothelial nitric oxide. J Biol Chem 277: 48803-48807, 2002.

28. Kawashima S, Yamashita T, Ozaki M, Ohashi Y, Azumi H, Inoue N, Hirata K, Hayashi Y, Itoh $\mathrm{H}$ and Yokoyama M: Endothelial NO synthase overexpression inhibits lesion formation in mouse model of vascular remodeling. Arterioscler Thromb Vasc Biol 21: 201-207, 2001.

29. Matoba T, Shimokawa H, Nakashima M, Hirakawa Y, Mukai Y, Hirano K, Kanaide $\mathrm{H}$ and Takeshita A: Hydrogen peroxide is an endothelium-derived hyperpolarizing factor in mice. J Clin Invest 106: 1521-1530, 2000
30. Morikawa K, Shimokawa H, Matoba T, Kubota H, Akaike T, Talukder MA, Hatanaka M, Fujiki T, Maeda H, Takahashi S and Takeshita A: Pivotal role of $\mathrm{Cu}, \mathrm{Zn}$-superoxide dismutase in endothelium-dependent hyperpolarization. J Clin Invest 112: 1871-1879, 2003.

31. Burgoyne JR, Madhani M, Cuello F, Charles RL, Brennan JP, Schröder E, Browning DD and Eaton P: Cysteine redox sensor in PKGIa enables oxidant-induced activation. Science 317: 1393-1397, 2007

32. Weber H, Klamer D, Freudenberg F, Kittel-Schneider S, Rivero O, Scholz CJ, Volkert J, Kopf J, Heupel J, Herterich S, et al: The genetic contribution of the NO system at the glutamatergic post-synapse to schizophrenia: further evidence and meta-analysis. Eur Neuropsychopharmacol 24: 65-85, 2014.

33. Steinert JR, Chernova T and Forsythe ID: Nitric oxide signaling in brain function, dysfunction and dementia. Neuroscientist 16: 435-452, 2010

34. Zhou QG, Zhu LJ, Chen C, Wu HY, Luo CX, Chang L and Zhu DY: Hippocampal neuronal nitric oxide synthase mediates the stress-related depressive behaviors of glucocorticoids by downregulating glucocorticoid receptor. J Neurosci 31: 7579-7590, 2011

35. Pogun S and Kuhar MJ: Regulation of neurotransmitter reuptake by nitric oxide. Ann N Y Acad Sci 738: 305-315, 1994

36. Silva M, Aguiar DC, Diniz CR, Guimarães FS and Joca SR: Neuronal NOS inhibitor and conventional antidepressant drugs attenuate stress-induced fos expression in overlapping brain regions. Cell Mol Neurobiol 32: 443-453, 2012.

37. Hou Z, Xie L, Yu L, Qian X and Liu B: MicroRNA-146a is down-regulated in gastric cancer and regulates cell proliferation and apoptosis. Med Oncol 29: 886-892, 2012.

38. Srivastava K and Srivastava A: Comprehensive review of genetic association studies and meta-analyses on miRNA polymorphisms and cancer risk. PLoS One 7: e50966, 2012.

39. Xu Z, Zhang L, Cao H and Bai B: MiR-146a rs2910164 G/C polymorphism and gastric cancer susceptibility: A meta-analysis. BMC Med Genet 15: 117, 2014.

40. Permuth-Wey J, Thompson RC, Burton Nabors L, Olson JJ, Browning JE, Madden MH, Ann Chen Y and Egan KM: A functional polymorphism in the pre-miR-146a gene is associated with risk and prognosis in adult glioma. J Neurooncol 105: 639-646, 2011.

41. Wang J, Bi J, Liu X, Li K, Di J and Wang B: Has-miR-146a polymorphism (rs2910164) and cancer risk: A meta-analysis of 19 case-control studies. Mol Biol Rep 39: 4571-4579, 2012.

42. Li D, Wang T, Song X, Qucuo M, Yang B, Zhang J, Wang J, Ying B, Tao C and Wang L: Genetic study of two single nucleotide polymorphisms within corresponding microRNAs and susceptibility to tuberculosis in a Chinese Tibetan and Han population. Hum Immunol 72: 598-602, 2011.

43. Alcaïs A, Quintana-Murci L, Thaler DS, Schurr E, Abel L and Casanova JL: Life-threatening infectious diseases of childhood: Single-gene inborn errors of immunity? Ann N Y Acad Sci 1214: 18-33, 2010.

44. Alter A, Fava VM, Huong NT, Singh M, Orlova M, Van Thuc N, Katoch K, Thai VH, Ba NN, Abel L, et al: Linkage disequilibrium pattern and age-at-diagnosis are critical for replicating genetic associations across ethnic groups in leprosy. Hum Genet 132: 107-116, 2013. 